Journal of Molecular Structure, 37 (1977) 113-126

- Elsevier Scientific Publishing Company, Amsterdam - Printed in The Netherlands

\title{
MOLECULAR STRUCTURES OF NEOPENTANE AND DI-TERT- BUTYLMETHANE BY VAPOR-PHASE ELECTRON DIFFRACTION
}

\author{
L. S. BARTELL and W. F. BRADFORD \\ Department of Chemistry, University of Michigan, Ann Arbor, Michigan 48109 (U.S A.)
}

(Received 13 July 1976)

\begin{abstract}
Al though the present molecules are much less strained than the tri-t-butyl member of the series $\mathrm{CH}_{\mathrm{n}}(\mathrm{t}-\mathrm{Bu})$. $\rightarrow$ studied previously, di-t-butylmethane nevertheless exhibits striking steric deformations due to its pair of inescapable GG' conformations. The two adjacent $t$-butyl groups respond to the steric stress by undergoing torsional displacements of $15 \pm 6^{\circ}(3 a)$, by tilting away from each other by $3-5^{\circ}$, and by opening up the central CCC bond angle to $125-128^{\circ}$ (parameter value sensitive to assumptions in analysis). Carbon-carbon bonds, with mean lengths of $1.545 \pm 0.005 \AA$, are stretched on the average by about $0.008 \mathrm{~A}$ from the neopentane reference value. Derived molecular parameters are in substantial agreement with values calculated by molecular mechanics using model fields MUB-1 and MUB-2. The methylene ' $\mathrm{C}-\mathrm{H} \mathrm{nmr}$ coupling constant was found to be $125 \mathrm{~Hz}$, a value indistinguishable from those reported for unstrained alkanes but not in accord with predictions from the formulas of Foote or Mislow for severely distorted methylene groups.

Molecular parameters for neopentane included $r_{\mathrm{g}}(\mathrm{C}-\mathrm{C})=1.534 \pm 0.003 \mathrm{~A}, r_{\mathrm{g}}(\mathrm{C}-\mathrm{H})$ $=1.114 \pm 0.008 \AA$ and $\angle C C H=112 \pm 3^{\circ}$. The new value for the $C-C$ bond satisfactorily resolves a discrepancy between previously reported bond lengths. These had disagreed significantly with each other but, to within their uncertainties, they are consistent with the new, intermediate value. Amplitudes of vibration were determined for both neopentane and di-t-butylmethane.
\end{abstract}

\section{INTRODUCTION}

As part of a continuing program of structural research on hydrocarbons $[1,2]$ the study of mono- and di-tert-butylmethane (neopentane and 2,2,4,4tetramethylpentane) was initiated. These molecules are homologues of tri-tert-butylmethane (TTBM) which, in an earlier investigation [3] proved to be remarkable because of its large steric deformations. It is reasonable to expect di-tert-butylmethane (DTBM) to be significantly less strained than TTBM because the smaller congestion around the central carbon atom gives tha tert-butyl groups more freedom to move apart and relieve steric interactions. The possibility of obtaining steric deformations of various magnitudes provides opportunities for testing theories of intramolecular forces and other properties such as carbon-13 coupling constants and their relation to bond angles and orbital hybridization [4-7]. 
Neopentane, on the other hand, is generally considered to be unstrained. It has been the subject of several previous electron diffraction studies [8-12] which disagree among themselves by more than is acceptable for an example serving as the prototype of a molecule with a quaternary carbon atom.

\section{EXPERIMENTAL}

A sample of neopentane with a stated purity of 99.88 mole percent was purchased from the Phillips Petroleum Company. It was used as received. A sample of DTBM was obtained from the Chemical Samples Company with a stated purity of 99 mole percent. After receipt it was triple vacuum distilled and used without further treatment.

Diffraction patterns were recorded at room temperature with $40 \mathrm{kV}$ incident electrons on $4 \times 5$ inch Kodak Electron Image plates with the electron diffraction unit at the University of Michigan [13]. Data were obtained at both the 21-cm and 11-cm camera distances through an $r^{3}$ sector and, in the case of DTBM, at the 21-cm camera distance through an $r^{2}$ sector. Detailed experimental conditions are given in Table 1 , and a description of the processing and reading of photographic plates is presented in a dissertation [14].

Absorbances, $A$ of the diffraction patterns were converted into relative intensities (exposures), $E$, by [14]

$E=A\left(1+0.116 A+0.0179 A^{2}+0.00312 A^{3}\right)$

Five apparently flawless plates from each camera geometry were selected to be averaged in the analysis. The averaged data sets at each camera distance were interpolated to integral $q$ values. In the case of DTBM this reduced $15021-\mathrm{cm}\left(r^{3}\right)$ values to $58,14311-\mathrm{cm}\left(r^{3}\right)$ values to 101 , and $8421-\mathrm{cm}$ $\left(r^{2}\right)$ values to 32 . Similar numbers were involved for neopentane.

A carbon-13 nmr spectrum of DTBM was obtained on a Jeol PFT-100 Fourier transform spectrometer by Mr. Frank Parker of our department.

TABLE 1

Experimental conditions under which diffraction patterns of neopentane and di-tertbutylmethane were recordeda

\begin{tabular}{|c|c|c|c|c|c|}
\hline Camera geometry & $\mathrm{C}_{5} \mathrm{H}_{12}$ & $\mathrm{C}_{5} \mathrm{H}_{12}$ & $\mathrm{C}_{9} \mathrm{H}_{20}$ & $\mathrm{C}_{9} \mathrm{H}_{20}$ & $\mathrm{C}_{9} \mathrm{H}_{20}$ \\
\hline $\begin{array}{l}\text { Camera distance }(\mathrm{cm}) \\
\text { Sector (radius, } \mathrm{cm}) \\
\text { Gample temperature }\left({ }^{\circ} \mathrm{C}\right)\end{array}$ & $\begin{array}{c}21.117 \\
r^{3}(4.8) \\
29\end{array}$ & $\begin{array}{c}11.042 \\
r^{3}(4.8) \\
29\end{array}$ & $\begin{array}{l}21.094 \\
r^{2}(3.2) \\
26\end{array}$ & $\begin{array}{l}21.160 \\
r^{3}(4.8) \\
26\end{array}$ & $\begin{array}{l}10.919 \\
r^{3}(4.8) \\
26\end{array}$ \\
\hline Sample pressure (torr) & 100 & 100 & 20 & $\mathbf{2 0}$ & 20 \\
\hline Exposure time (s) & $2-3$ & $8-12$ & 0. & $8.0-20.0$ & $25.0-4$ \\
\hline Beam current $(\mu \mathrm{A})$ & 0.45 & 0.42 & 0.75 & 0.58 & 0.74 \\
\hline Nozzle to beam distance ( $\mathrm{cm}$ & 0.050 & 0.050 & 0.035 & 0.043 & 0.044 \\
\hline Number of plates averaged & 5 & 5 & 5 & 5 & 5 \\
\hline
\end{tabular}

a Electron wavelength 0.060153 \& for all plates. 
Experimental intensities were corrected for sector irregularities and extraneous scattering before being reduced to experimental leveled intensities $[13,14], I_{\mathrm{o}}(s)$, by dividing by the theoretical atomic intensity function. The partial wave elastic scattering factors of Schafer et al. [15] and the inelastic scattering factors of Tavard et al. were used throughout the analysis.

It was assumed that neopentane molecules possess $T_{\mathrm{d}}$ symmetry and can therefore be described in terms of three structural parameters. The molecule DTBM is more challenging. If it is assumed that DTBM has at most an overall $C_{2}$ symmetry, the radial distribution function will be composed of 207 different internuclear distances grouped into seven peaks, not all of which are well defined. It requires forty-one geometric parameters to describe the most general model of this symmetry. If one further assumes (1) that the t-butyl and methyl groups posses $C_{3}$ symmetry; (2) that the plane defined by the methylene group ( $\mathrm{HCH}^{\prime}$ ) is perpendicular to the plane defined by the three central carbon atoms $\left(\mathrm{C}_{2} \mathrm{CC}_{2}^{\prime}\right) ;(3)$ that the $\mathrm{HCH}$ angle of the weakly scattering methylene group is $105^{\circ}$; and (4) that all $\mathrm{C}-\mathrm{H}$ bond lengths are the same; then the number of geometric parameters reduces to nine. These nine parameters (see Fig. 1 for the numbering scheme for atoms) are:

(1) $r_{\mathrm{g}}(\mathrm{CC})$, average $\mathrm{CC}$ bond length.

(2) $\Delta$, difference between $C C$ bond lengths (see following text).

(3) $r_{\mathrm{g}}(\mathrm{CH})$, average $\mathrm{CH}$ bond length.

(4) $\alpha\left(\mathrm{C}_{2} \mathrm{CC}_{2}^{\prime}\right)$, central $\mathrm{CCC}$ bond angle.

(5) $\alpha(C C C)$, average tert-butyl CCC bond angle.

(6) $\alpha(\mathrm{CCH})$, average methyl $\mathrm{CCH}$ bond angle.

(7) $\tau(\mathrm{t}-\mathrm{Bu})$, torsional displacement of the tert-butyl groups, where a positive value represents a counterclockwise rotation when looking from the tertbutyl group towards the central carbon atom along the $\mathrm{CC}$ bond. The zero reference is taken to be the staggered conformation between the tert-group and the methylene $\mathrm{CH}$ bonds.

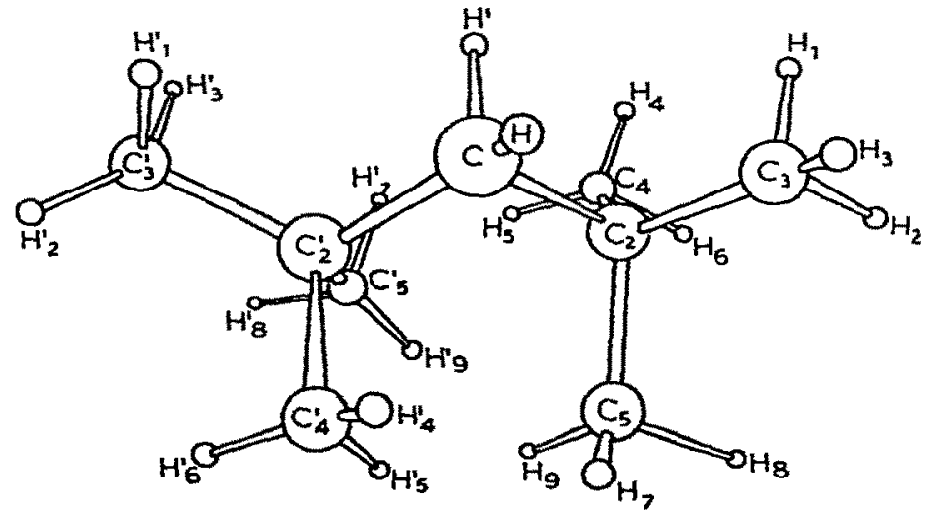

Fig. 1. Numbering scheme for atoms in di-tert-butylmethane. 
(8) $\tau$ (Me), torsional displacement of the methyl groups, where a positive value represents a counterclockwise rotation when looking from the methyl carbon atom towards the central tert-butyl carbon atom along the $\mathrm{CC}$ bond. The zero reference is taken to be the staggered conformation of the methyl group with respect to the tert-butyl carbon skeleton.

(9) $\epsilon$, tilt of t-butyl groups about an axis through their central carbon atom perpendicular to the plane defined by $\mathrm{C}_{2} \mathrm{CC}_{2}^{\prime}$. A positive tilt angle increases the clearances between the two t-butyl groups.

Obviously, this reduction of parameters obscures the significance of the 41 individual parameters but it is not expected to degrade the structure analysis seriously.

The structure parameters were refined by comparing observed and calculated molecular intensity functions by a least squares procedure and by a comparison of experimental and theoretical radial distribution functions $[13,16,17]$. A diagonal weight matrix with diagonal elements $\left(s / s_{\mathrm{max}}\right)^{2}$ was used in all refinements of intensities. Estimated uncertainties inciuded effects of data correlation via the model of Bartell and Anashkin [ 8 8]. Morse asymmetry constants [19] $a=2$ were assigned to all internuclear distances. The data for the several camera geometries were treated separately until their background functions were established using the usual criteria; then the data were interpolated to integral intervals of $\pi / 10$ in $s$-space, and blended together. Experimental leveled intensities and background functions are available as supplementary information*. Details of background functions and structure refinements are given below.

\section{Neopentane}

A background function of form $\left[A \exp (-0.105 s)+\sum_{n=0}^{3} a_{n} s^{n}\right]$ was adopted to represent the 21-cm data, where $A$ and the $a_{n}$ were refined by least squares in preliminary structure analyses, and a hand-drawn background was applied to the $11-\mathrm{cm}$ data. Nonbonded distances were corrected for the Bastiansen-Morino shrinkages listed in Table 2. These values were estimated from shrinkages calculated for propane [20], $\mathrm{CH}_{4}$, and $\mathrm{CF}_{4}[21]$ and can be expected to be only approximately correct for neopentane.

\section{Di-tert-butylmethane}

Background functions were taken to be of form $\left[A \exp (-0.43 s)+\sum_{n=0}^{4} a_{n} s^{n}\right]$ for the $21-\mathrm{cm}$ data $\left(r^{3}\right.$ sector $), \sum_{n=0}^{4} a_{n} s^{4}$ for the $21-\mathrm{cm}$ data $\left(r^{2}\right.$ sector), and TABLE 2

Estimated shrinkages for neopentane in $\mathbf{A}$

\begin{tabular}{llll}
\hline $1,3 \mathrm{C} \ldots \mathrm{C}$ & 0.0027 & $1,4 \mathrm{C} \ldots \mathrm{H}$ & 0.021 \\
$1,3 \mathrm{C} \ldots \mathrm{H}$ & 0.013 & $(\mathrm{H} \cdots \mathrm{H})_{\text {ave }}$ & 0.018 \\
\hline
\end{tabular}

* Available as Supplementary Publication No. SUP 26049 (4 pages) from the British Library Lending Division (BLL), Boston Spa, Wetherby, Yorkshire LS23 7BQ. 
$\sum_{n=0}^{5} \alpha_{n} s^{n}$ for the 11-cm data. Shrinkage corrections were estimated from the "practical shrinkages" calculated in a normal coordinate treatment of $n$-butane $[14,22]$. The values used are included in the supplementary information available from BLLD.

Once a preliminary structure had been found, the contributions calculated for all hydrogen-hydrogen pair scatterings were subtracted from the intensity data except for the $1,3 \mathrm{H} \cdot \cdots \mathrm{H}$ scatterings which were retained. This scheme reduced the cost of analyses at little sacrifice of precision.

Although insufficient resolving power is available to distinguish between all four different types of $\mathrm{C}-\mathrm{C}$ bonds in DTBM, it was felt to be worthwhile to see if some discrimination could be made. Therefore two different $\mathrm{CC}$ bond distances were incorporated into the molecular model. In the case of TTBM the central CC bonds had been found to be significantly longer than the peripheral bonds in the tert-butyl groups. For DTBM the bond differentiation was carried out in the least squares refinement of the in tensity function according to two different points of view embodied in two different models (Table 3). Model I differentiates central bonds from the outer in the same way as was done in the case of TTBM. Model II apportions lengths differently as suggested by a "molecular mechanics" study of DTBM by model force field MUB-1 [1] .

Neither model proved to be significantly better in accounting for the diffraction intensities than the model for which all $\mathrm{CC}$ distances were taken to be equivalent. The standard deviation of the CC distance parameter $\Delta$ for each model was twice the value obtained for $\Delta$ itself. An identical value of the average $\mathrm{CC}$ bond length was found for all models.

The MUB-1 molecular mechanics results also indicated that the various $1,3 \mathrm{C} \cdot-\mathrm{C}$ non-bonded distances were significantly different from each other. In order to incorporate the principal effect of this into the least squares refinement of the intensity without allowing the number of independent parameters to increase greatly, it was decided to allow the t-butyl groups to tilt by parameter $\epsilon$ described above.

Although the magnitude of the methyl torsional angle is obtainable from electron diffraction, the direction of displacement is not. The distribution of inter-t-butyl group $\mathrm{C} \cdot$.. H distances is only modestly dependent upon the signs of the torsional displacement. In order to examine this effect more closely, the sign (rotational direction) for one methyl group in each

TABLE 3

Models representing distribution of bond lengths in DTBM

\begin{tabular}{|c|c|}
\hline Model I & Model II \\
\hline $\begin{array}{l}r_{g}\left(C C_{2}\right)=r_{g}(C C)_{\text {ave }}+\Delta \\
r_{g}\left(C_{2} C_{3}\right)=r_{g}(C C)_{\text {ave }}-1 / 3 \Delta \\
r_{g}\left(C_{2} C_{4}\right)=r_{g}(C C)_{\text {ave }}-1 / 3 \Delta \\
r_{g}\left(C_{2} C_{s}\right)=r_{g}(C C)_{\text {ave }}-1 / 3 \Delta\end{array}$ & $\begin{array}{l}r_{g}\left(C C_{2}\right)=r_{g}(C C)_{\text {ave }}+1 / 2 \Delta \\
r_{g}\left(C_{2} C_{3}\right)=r_{g}(C C)_{a v e}+1 / 2 \Delta \\
r_{g}\left(C_{2} C_{4}\right)=r_{g}(C C)_{a v e}-1 / 2 \Delta \\
r_{g}\left(C_{2} C_{s}\right)=r_{g}(C C)_{\text {ave }}-1 / 2 \Delta\end{array}$ \\
\hline
\end{tabular}


t-butyl group was constrained in one run to be opposite from the sign for the remaining two. The average torsional magnitude converged to within two standard deviations of the previously determined value.

Finally, in consultation with Dr. R. R. Sharp, the carbon-13 nmr spectrum of DTBM-was analyzed for the carbon-13 hydrogen coupling constants of the methyl and methylene hydrogens.

\section{RESULTS}

The reduced molecular intensity curves with plots of the associated residuals are shown in Figs. 2 and 4 . Indices of resolution for neopentane were 0.95 and 0.93 for the $11-\mathrm{cm}$ and $21-\mathrm{cm}$ data, respectively. For DTBM the corresponding indices were 1.09 and 0.99 , and a value of 0.80 was obtained for the $21-\mathrm{cm}, r^{2}$ sector data. Radial distribution functions are displayed with residuals in Figs. 3 and 5.

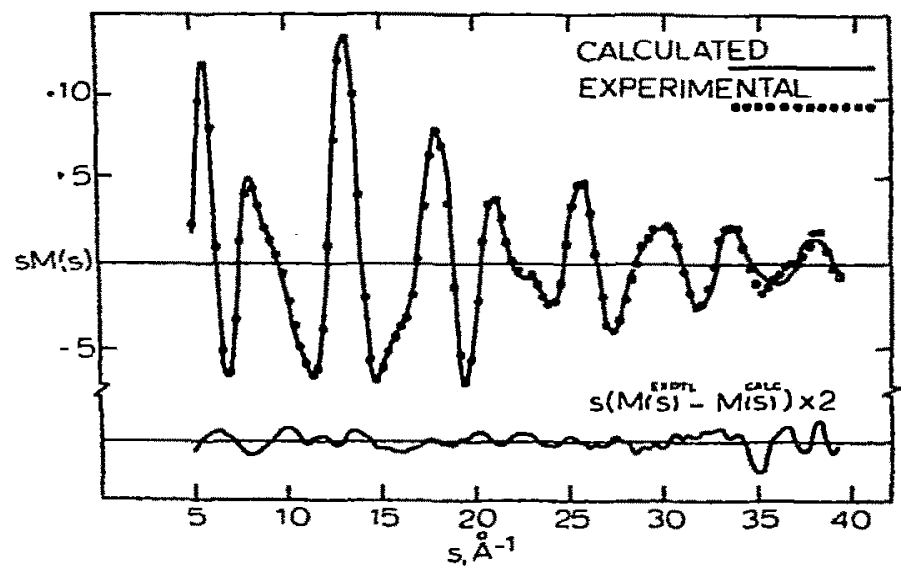

Fig. 2. Molecular intensity curve for neopentane.

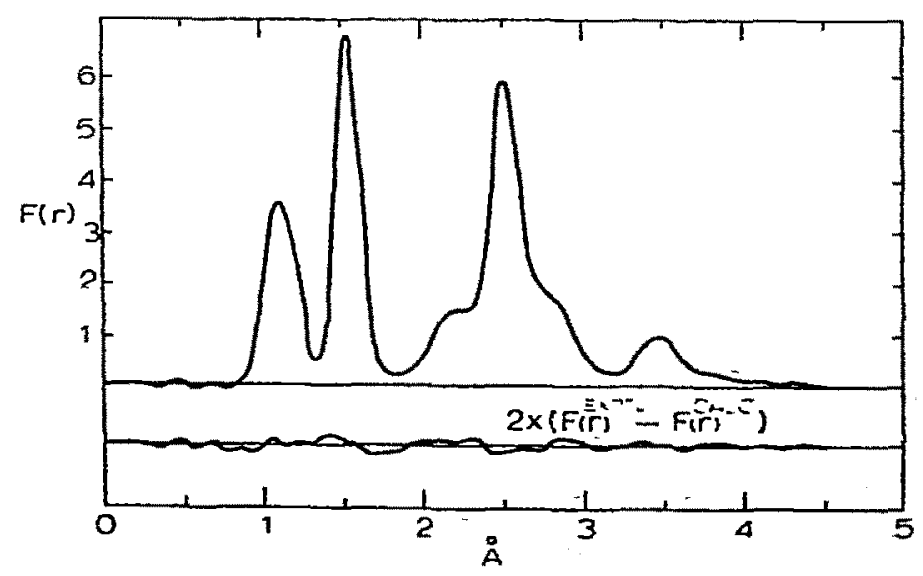

Fig- 3. Experimental radial distribution function for neopentane. 


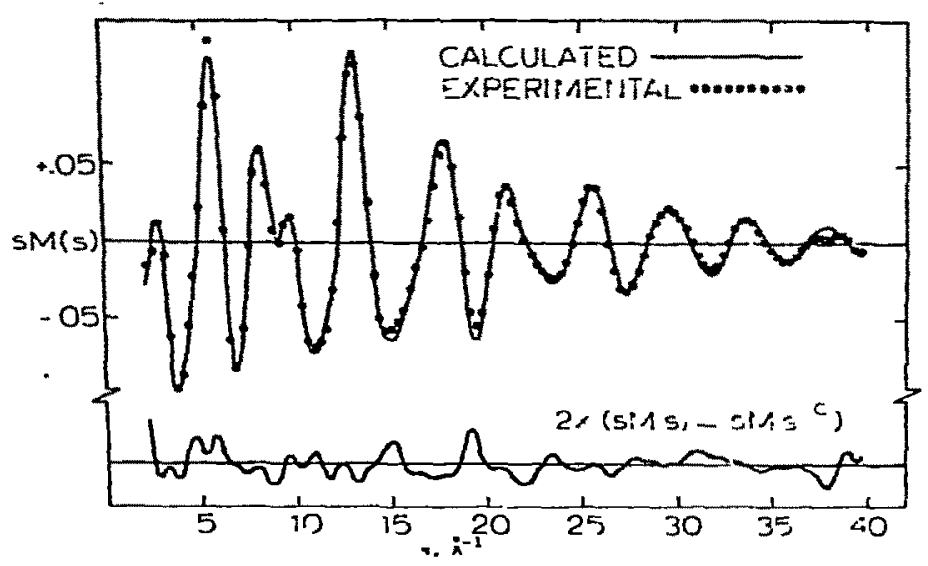

Fig. 4. Molecular intensity curve for di-tert-butylmethane.

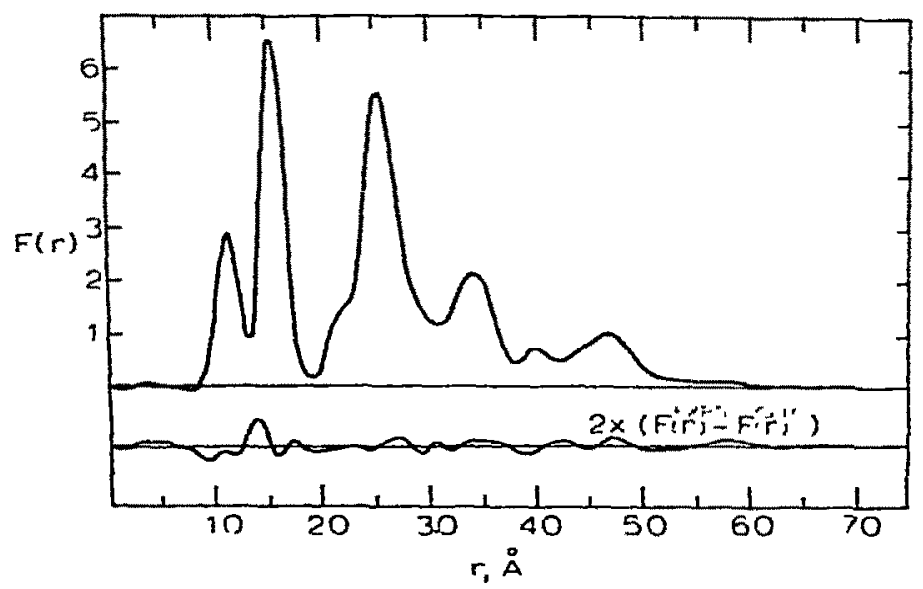

Fig. 5. Experimental radial distribution function for di-tert-butylmethane.

The structure parameters found in this investigation are presented in Tables 4 and 6 with the corresponding correlation matrices tabulated in Tables 5 and 7. Structure parameters calculated by molecular mechanics are compared with the electron diffraction results in Table 8.

The nmr coupling constants $J\left({ }^{13} \mathrm{C}-\mathrm{H}\right)$ for both the methylene hydrogens were, at $125 \mathrm{~Hz}$, identical with those for the methyl hydrogens.

\section{DISCUSSION}

\section{Neopentane}

The results of this study $\left[r_{\mathrm{g}}(\mathrm{C}-\mathrm{C})=1.537(3)\right]$ lie between the unpublished results of Roth and Bartell $\left[r_{\mathrm{g}}(C-C)=1.533(4)\right][10]$ and those of Zeil et al. $\left[r_{\mathrm{a}}(\mathrm{C}-\mathrm{C})=1: 540\right.$, implying $\left.r_{\mathrm{g}}=1.542\right][11]$ and Beagley et al. $\left[r_{\mathrm{a}}(\mathrm{C}=\mathrm{C})=1.541(6)\right.$, implying $\left.r_{\mathrm{E}}=1.543\right]-[12]$; all uncertainties corresponding to 30 (estimated). Even though the previous results (ref. 10 on the one hand, 


\section{TABLE 4}

Structural parameters ${ }^{a}$ and estimated errors ${ }^{b, c}$ for neopentane

\begin{tabular}{lllll}
\hline Parameter & $r_{\mathrm{g}}$ & $l_{\mathrm{g}}$ & Angled $^{\mathrm{d}}$ \\
\hline CC & $1.537(3)$ & $0.051(4)$ & \\
CH & $1.114(8)$ & $0.079(8)$ & \\
CCH & $2.200(12)$ & $0.110(13)$ & $112.2(2.8)$ \\
C - C & $2.508(3)$ & $0.071(3)$ & \\
$1,4 \mathrm{C} \cdot-\mathrm{H}$ & $2.767(15)$ & $0.167(16)$ & \\
$1,4 \mathrm{C} \cdot-\mathrm{H}$ & $3.480(9)$ & $0.106(19)$ & \\
$R(21-\mathrm{cm})=0.93$ & & & & \\
$R(11-\mathrm{cm})=0.95$ & & & & \\
$\sigma(I) / U)=0.0017$ & & & &
\end{tabular}

a Distances and amplitudes are in $\AA$, angles in degrees and $R$ and $\sigma(I) / U)$ are dimensionless. $b$ All estimated uncertainties include both systematic and random errors and correspond to $3 \sigma$ where $\sigma$ is the estimated standard deviation from the zeroth-order error matrix augmented for $\mathrm{CC}$ and $\mathrm{CH}$ bonds by the effect of data correlation in accord with ref. 16 ,

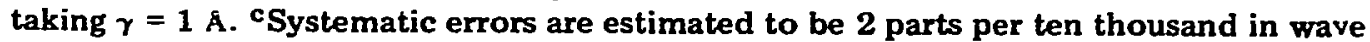
length, 4 parts per ten thousand in camera distance, and 2 parts per ten thousand in the radial measurement in microphotometer scanning. ${ }^{d}$ Bond angle uncertainties do not include any allowance for the uncertainties in the shrinkages used. Angles are based on an $r_{\alpha}$ structure.

\section{TABLE 5}

Standard deviations and correlation coefficients from zero-order error matrix ${ }^{\mathbf{a}}$ for neopentane

\begin{tabular}{|c|c|c|c|c|c|c|c|c|c|c|}
\hline & $\theta_{1} b$ & $\theta_{2}$ & $\theta_{3}$ & $\theta_{4}$ & $\theta_{5}$ & $\theta_{6}$ & $\theta_{7}$ & $\theta_{\mathrm{s}}$ & $\theta_{9}$ & $\theta_{10}$ \\
\hline$\sigma\left(\theta_{j}\right)^{C}$ & 0.50 & 1.53 & 0.32 & 0.72 & 1.10 & 1.48 & 4.26 & 5.48 & 6.34 & 0.012 \\
\hline$\theta$, & 1.0 & 0.01 & -0.02 & -0.05 & 0.01 & -0.02 & 0.12 & 0.26 & -0.03 & -0.05 \\
\hline$\theta_{2}$ & & 1.0 & -0.21 & 0.06 & 0.05 & 0.0 & -0.03 & 0.00 & 0.01 & 0.11 \\
\hline$\theta_{3}$ & & & 1.0 & 0.08 & -0.22 & 0.05 & 0.19 & -0.31 & -0.02 & 0.11 \\
\hline$\theta_{4}$ & & & & 1.0 & 0.29 & 0.30 & -0.01 & $-0.0^{n}$ & 0.11 & 0.66 \\
\hline$\theta_{s}$ & & & & & 1.0 & 0.20 & -0.10 & 0.35 & 0.07 & 0.44 \\
\hline$\theta_{6}$ & & & & & & 1.0 & -0.01 & -0.12 & 0.08 & 0.46 \\
\hline$\theta_{7}$ & & & & & & & 1.0 & $-0.1:$ & 0.00 & -0.01 \\
\hline$\theta_{3}$ & & & & & & & & 1.6 & -0.06 & -0.03 \\
\hline$\theta$ & & & & & & & & & 1.0 & 0.17 \\
\hline$\theta_{10}$ & & & & & & & & & & 1.0 \\
\hline
\end{tabular}

${ }^{a}$ Notation of ref. 18. ${ }^{b}$ The order of the parameters is: $1, r\left(C_{1}-C_{2}\right), 2, r\left(C_{1}-H_{1}\right) ; 3, \angle C C H$; $4, I\left(C_{1}-C_{2}\right) ; 5, I\left(C_{2}-C_{3}\right) ; 6, I\left(C_{1}-H_{1}\right) ; 7, I\left(C_{2}-H_{1}\right) ; 8, I\left(C_{3}-H_{2}\right) ; 9, I\left(C_{3}-H_{1}\right) ; 10, R$ (index of resolution. 'Distances in thousandths of an Angstrom unit, anfles in degrees, $R$ dimensionless.

refs. 11 and 12 on the other) disagree significantly with each other, they are not significantly different according to Cruickshank's criterion [23], from the present result to within experimental uncertainties. The present $C-C$ bond length appears to be the most precise. 
TABLE 6

Structural parameters ${ }^{a}$ and estimated errors ${ }^{b . c}$ for di-t-butylmethane, subject to constraint that all $\mathrm{C}-\mathrm{C}$ bond lengths are the same

\begin{tabular}{|c|c|c|c|}
\hline Parameter & $r_{\mathrm{g}}$ & $I_{\mathrm{d}}$ & Angled \\
\hline $\mathbf{C H}$ & $1.122(15)$ & $0.087(15)$ & \\
\hline CC & 1.545 (5) & 0.058 (5) & \\
\hline $\mathrm{C}_{2} \mathrm{CC}_{2}^{\prime}$ & $2.77 \quad$ (7) & $0.084(12)^{\mathrm{e}}$ & $128.0(6.0)$ \\
\hline $\mathrm{CC}_{2} \mathrm{C}_{3}$ & $2.533(42)^{f}$ & $0.084(12)^{e}$ & $107.5^{\mathrm{B}}$ \\
\hline $\mathrm{CC}_{2} \mathrm{C}_{3}$ & $2.485(42)^{f}$ & $0.084(12)^{\mathrm{e}}$ & $111.3^{5}$ \\
\hline $\mathrm{CC}_{2} \mathrm{C}_{5}$ & $2.498(42)^{f}$ & $0.084(12)^{\mathrm{e}}$ & $112.8^{8}$ \\
\hline $\mathrm{CCH}^{2}$ & $2.215(39)$ & $0.104(42)$ & $112.1(3.0)$ \\
\hline $\mathbf{H C H}^{\mathbf{1}}$ & $1.797(42)$ & $0.135(90)$ & \\
\hline$|r(t-B u)|_{\text {ave }}$ & & & $15.1(6.0)$ \\
\hline$|\tau(\mathrm{Me})|_{\text {ave }}$ & & & $13.2(7.0)^{h}$ \\
\hline Tilt $\epsilon$ & & & $3.1(23)^{1}$ \\
\hline $\mathrm{C}_{2} \mathrm{CC}_{2}{ }^{\prime} \mathrm{C}_{3}{ }^{\prime}$ & $3.96(8)$ & {$[0.0863]^{]}$} & \\
\hline $\mathrm{C}_{2} \mathbf{C C}_{2}^{2} \mathbf{C}_{3}^{3}$ & $348(10)$ & $0.11(9)^{k}$ & \\
\hline $\mathrm{C}_{2} \mathrm{CC}_{2}^{\prime} \mathrm{C}_{5}^{\prime}$ & $3.24(8)$ & $0.11(9)^{k}$ & \\
\hline$R\left(21-\mathrm{cm}, \mathrm{r}^{2}\right)=0.81(6)$ & & 0.80 & \\
\hline$R\left(21-\mathrm{cm}, r^{3}\right)=0.99(6)$ & & 0.99 & \\
\hline $\begin{array}{l}R\left(11-\mathrm{cm}, r^{3}\right)=1.09(6) \\
\sigma(I) /(I)=0.0015\end{array}$ & & 1.09 & \\
\hline
\end{tabular}

a Distances and amplitudes are in $A$, angles in degrees and $R$ and $\sigma(I) /(U)$ are dimensionless. See Fig. 1 for atom numbering. Distances and amplitudes tabulated refer to the first and last atoms listed under parameter. Derived parameters based on $\Delta=0$ constraint. ${ }^{b}$ See footnote $b$, Table 4 . ${ }^{c}$ See footnote $c$, Table 4 . ${ }^{d}$ See footnote $d$, Table 4 . ${ }^{\text {eThe methyl }}$ $1,3 \mathrm{CC}$ amplitudes were refined as a single parameter. ${ }^{\mathrm{f}}$ The methyl 1,3 $\mathrm{CC}$ distances are taken to be identical in the structure. ${ }^{\mathrm{g}}$ The methyl $\mathrm{CCC}$ angles were calculated from $\tau(t-\mathrm{Bu})$ and $\epsilon$ together with the mean $\mathrm{CC}_{2} \mathrm{C}_{\mathrm{Me}}$ angle of $110.6 \pm 2.8^{\circ}$, assuming local $\mathrm{C}_{3}$ symmetry for the $t$-butyl groups. h Subjectively doubled from least-squares value. 'In various refinements $\epsilon$ and $\alpha\left(C_{2} C_{2} C_{2}^{\prime}\right)$ were strongly correlated in accord with $c=3.1^{\circ}-$ $0.6 .\left(\alpha-128^{\circ}\right)$. This tends to preserve Me - M distances between t-butyl groups jThe trons 1,4 amplitude was constrained to the value estimated from a normal coordinate analysis of $\mathrm{n}$-butane. ${ }^{k}$ The gauche $1,4 \mathrm{CC}$ amplitudes were refined as a single parameter.

\section{Di-tert-butylmethane}

Clear evidence of steric deformations is evident in the experimental structure of DTBM. For one thing, the tilt parameter $\epsilon$ expressing avoidance of t-butyl groups is significantly different from zero. For another, it appears that inter-t-butyl interactions induce significant torsional displacements. These include twists of methyl groups away from perfectly staggered conformations, as reflected in the non-zero value of $\mid \tau$ (methyl)| in Table 6, and twists of t-butyl groups away from each other as manifested in the parameter $\tau$ (t-butyl). Even more striking is the central CCC bond angle of $125-128^{\circ}$ which is extremely large for a tetrahedrally coordinated central atom. "Unstrained" CCC bond angles about secondary carbons are more commonly $113^{\circ}-114^{\circ}[22-24]$. Even though the structure attests to the 


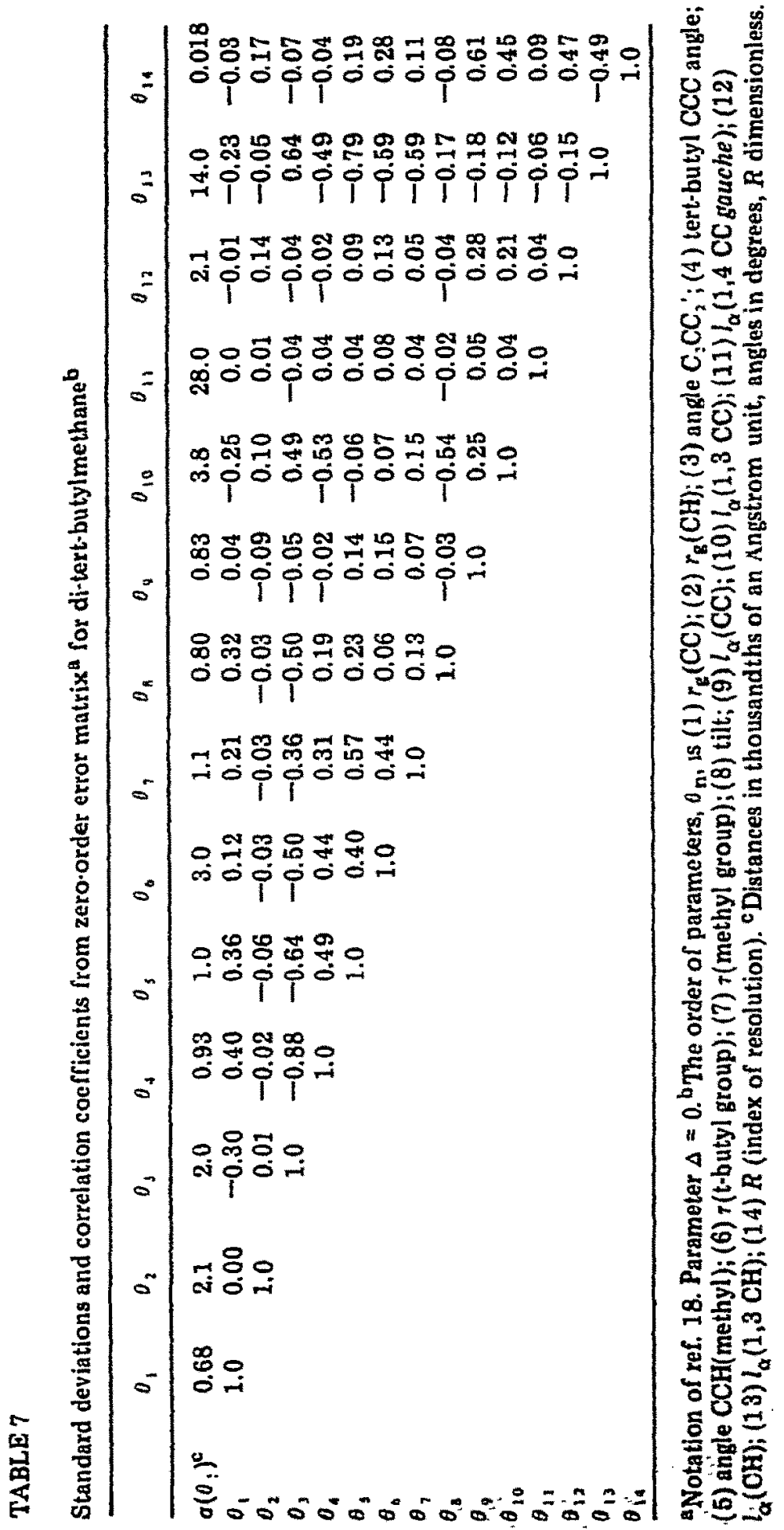


TABLE 8

Comparison between structural parameters for di-t-butylmethane obtained by electron diffraction, Model II, and molecular mechanics ${ }^{\mathbf{a}}$

\begin{tabular}{|c|c|c|c|c|}
\hline \multirow[t]{2}{*}{ Parameter } & \multicolumn{2}{|l|}{ E.D. } & \multicolumn{2}{|c|}{ Mol. Mech. } \\
\hline & $\Delta=0.02$ & $\Delta=0.00^{b}$ & MUB-1 & MUB-2 \\
\hline$r\left(C-C_{2}\right)$ & & & 1.552 & 1.549 \\
\hline$r\left(C_{2}-C_{3}\right)$ & & & 1.551 & 1.563 \\
\hline$r\left(C_{2}-C_{4}\right)$ & & & 1.537 & 1.534 \\
\hline$r\left(C_{2}-C_{5}\right)$ & & & 1.532 & 1.526 \\
\hline$r(C-C)_{\text {ave }}$ & 1.545 & 1.545 (5) & $\overline{1.543}$ & $\overline{1.543}$ \\
\hline $\mathrm{r}(\mathrm{CH})_{\text {ave }}$ & $\begin{array}{r}1.122 \\
1.051\end{array}$ & $1.122(15)$ & 1.114 & 1.113 \\
\hline$\angle \mathrm{CCH}$ & 112 & $112(3)^{\mathrm{d}}$ & $\begin{array}{l}104.4 \\
111.9\end{array}$ & $\begin{array}{l}103.8 \\
112.5\end{array}$ \\
\hline$\angle \mathrm{C}_{2} \mathrm{CC}_{2}{ }^{\prime}$ & 125 & $128(6)$ & 121.7 & 123.0 \\
\hline$\angle C \bar{C}_{2} C_{3}$ & 106.4 & $107.5^{e}$ & 107.3 & 107.0 \\
\hline$\angle C_{2} C_{3}$ & 112.6 & $111.3^{\mathrm{e}}$ & 111.3 & 111.8 \\
\hline$\angle \mathrm{CC}_{2} \mathrm{C}_{5}$ & 115.2 & $112.8^{e}$ & 113.1 & 113.1 \\
\hline tilt $\epsilon$ & 5.2 & $3.1(2.3)$ & - & - \\
\hline$\tau\left(\mathrm{HCC}_{2} \mathrm{C}_{3}\right)$ & 16.4 & $15.1^{f}$ & 16.8 & 13.5 \\
\hline$\tau\left(\mathrm{HCC}_{2} \mathrm{C}_{3}\right)$ & 256.4 & $255.1^{f}$ & 259.4 & 256.2 \\
\hline$\tau\left(\mathrm{HCC}_{2} \mathrm{C}_{5}\right)$ & 136.4 & 135.1 & 135.3 & 131.8 \\
\hline$|\tau(\mathrm{Me})|_{\text {ave }}$ & 12 & $13(6)$ & 5.5 & 4.2 \\
\hline
\end{tabular}

a Distances are in $\mathrm{A}$, angies in degrees. See $F_{1 g} 1$ for atom numbering The parameters of field MUB-1 are from ref. 1 and $C-C$ bond lengths have been reduced by $0.010 \mathrm{~A}$ as suggested in ref. 1 results. The parameters of field MUB-2 are from $S$. Fitzwater and L. S. Bartell, J. Am. Chem. Soc., 98 (1976) 5107 . b Uncertainties for electron diffraction results represent $3 \sigma .{ }^{c}$ Assumed. $d$ Values represent the average of all 18 methyl $C C H$ angles. The methyl CCC angles were calculated from $\tau(t-B u)$ and $\epsilon$ together with the mean $\mathrm{CC}_{2} \mathrm{C}_{\mathrm{Me}}$ angle of $111.5(\Delta=0.02)$ or $110.6(\Delta=0)$, assuming local $C_{3}$ symmetry for the $t$-butyl groups. 'The t-butyl torsional angles for the individual methyl groups are calculated from the average angle determined from staggered of 16.5 or $15.1 \div 6.0^{\circ}$ assuming $C_{3}$ symmetry for the t-butyl group

steric strain of the molecule, the $\mathrm{nmr}$ spectrum does not, notwithstanding prior evidence that ${ }^{13} \mathrm{C}-\mathrm{H}$ coupling constants are sensitive gauges of bond angle deformations.

Displacements of $\mathrm{C}^{13} \mathrm{CC}$ bond angles away from the unstrained value have been found in the past to correlate remarkably closely with ${ }^{13} \mathrm{C}-\mathrm{H} \mathrm{nmr}$ coupling constants for protons bonded to the vertex carbon-13 atom. This correlation has been attributed to changes in "hybridization" [4-7] around the central carbon. Foote [6] compared the coupling constants of several cyclic compounds where the $\mathrm{CCC}$ bond angles varied over a wide range. When the coupling constants were plotted against the corresponding CCC bond angles, a nearly straight line resulted, in spite of the fact that hybridization would be expected to be more closely related to the interorbital rather than the inter-atomic angles. The above correlation permitted 
estimations of $\mathrm{CCC}$ bond angles once the coupling constants were known. Mislow [7] pointed out that any departure from the tetrahedral angle which is induced by the geometric constraint of ring formation disturbs the $\sigma$ character of the bonds and results in "bond bending". He also postulated that with increasing angle bending, there is a corresponding change in hybridization and, on this basis, he derived a non-linear analytical expression between the CCC bond angles and the coupling constants which gave good agreement with both the observed values and Foote's empirical straight line.

In the present investigation, the nmr spectrum of DTBM yielded coupling constants for both the methylene and methyl hydrogens of $125 \mathrm{~Hz}$. According to the empirical relations of Mislow, the central CCC bond angle corresponding to $125 \mathrm{~Hz}$ should be approximately $109.5^{\circ}$, the idealized " $s p^{3 "}$ hybridization value. Alternatively, if the coupling constants are calculated according to Mislow from the CCC bond angles actually observed, DTBM is predicted on the basis of a $128^{\circ} \mathrm{CCC}$ bond angle to have a methylene coupling constant of $113.8 \mathrm{~Hz}$. Exactly analogous discrepancies were found, also, in the case

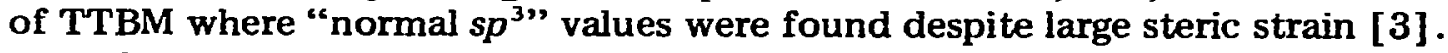
Therefore, it appears that a more fundamental theoretical approach is needed, an approach not based upon a preconceived hybridization scheme, before structural influences upon coupling constants can be understood. Experimental evidence to date indicates that the empirical scheme works well when CCC bond angles are forced to decrease (nncreasing the "s-character" of $\mathrm{C}-\mathrm{H}$ bonds) but fails when CCC angles are forced to increase from their unstrained values. A resolution of the problem will surely shed light on orbital following in bond bending displacements.

The relatively good agreement between the experimental and calculated results listed in Table 8 lends credibility to the derived structure parameters. Although the structural feature of most interest, the central CCC valence angle, is not very precisely reproduced, the discrepancy is scarcely outside the experimental uncertainty*. Now, the distortion of this angle is induced sterically by gauche-gauche' (GG') interactions from which the DTBM molecule cannot escape. In less highly strained branched hydrocarbons it is usually assumed that GG' conformations do not occur in appreciable concentrations. The molecule DTBM can relieve this strain quite effectively by opening up the central CCC bond angle and by twisting its t-butyl groups. By contrast, the molecule TTBM [3], which suffers even more GG' in teractions and which has less freedom to deform its central $\mathrm{CCC}$ bond angles, must resort to lengthening its central CC bonds substantially as well as to opening its CCC angles in order to relieve its strain. Although no such large bond length differentiation occurs with DTBM as evinced by the fact that the parameter $\Delta$ was too small to be established in least squares refinements, the

\footnotetext{
* Note added in proof: Professor N. L. Allinger (private communication) has applied his force field to DTBM. Results were similar to those of MUB-2 except for the central CCC angle, for which he obtained $127.8^{\circ}$.
} 
diffraction data do indicate an appreciable bond length strain. This is seen most directly in the mean bond length which is nearly $0.01 \AA$ longer than that in neopentane. It is also suggested by the breadth of the $\mathrm{CC}$ bond peak (mean amplitude $0.058 \AA$ ); this relatively great breadth hints that there may be a distribution of bond lengths.

The large CCC bond angle in DTBM is not without precedent. Bunn and Holmes [25] report a polymer X-ray diffraction value of $126^{\circ}$ for the corresponding $\mathrm{CCC}$ bond angle in polyisobutene. This polymer, which has pairs of methyl groups on al ternate chain atoms, is encumbered with unavoidable $\mathrm{GG}^{\prime}$ interactions exactly analogous to those in DTBM. These interactions are relieved by the opening up of the CCC angle together with torsional displacements.

Other compounds somewhat related to DTBM are di-tert-butylnitroxide [26] with a reported central angle of $136 \pm 3^{\circ}$, di-tert-butylketone [27] with a central angle which has been estimated to be perhaps in the range of $130-137^{\circ}$, and bis (trimethylgermyl) ketene [28] with a reported central angle of $127.6 \pm 1.3^{\circ}$. These compounds, possessing trigonal rather than tetrahedral coordination, would be expected to display larger bond angles. That the $\mathrm{Ge}-\mathrm{C}-\mathrm{Ge}$ bond angle is not as large as the $\mathrm{C}-\mathrm{N}-\mathrm{C}$ and $\mathrm{C}-\mathrm{C}-\mathrm{C}$ angles listed above illustrates that the stress in the germyl compound is smaller by virtue of the larger nonbonded clearances associated with the naturally long $\mathrm{Ge}-\mathrm{C}$ bonds. Analogously, it has been found that $\left.\left[\left(\mathrm{CH}_{3}\right)_{3} \mathrm{Si}\right)\right]_{3} \mathrm{SiH}$ [29] experiences much smaller steric strain than $\left[\left(\mathrm{CH}_{3}\right)_{3} \mathrm{C}\right]_{3} \mathrm{CH}$ [3]. In any event, it is noteworthy that the large steric requirements long known, qualitatively, to be associated with t-butyl groups can be measured quantitatively by their observed structural effects and, further, that these can now be accounted for with good success by model force field approaches.

\section{ACKNOWLEDGEMENTS}

This research was supported by a grant from the National Science Foundation. We also gratefully acknowledge a generous allowance of computing time from the Michigan Computing Center. We are deeply indebted to Mr. Frank Parker and Professor Robert Sharp for their assistance in the nmr work. We thank Dr. Susan Fitzwater for the molecular mechanics calculations with field MUB-2.

\section{REFERENCES}

1 E. J. Jacob, H. B. Thompson and L. S. Bartell, J. Chem. Phys., 47 (1967) 3736.

2 W. J. Adams and L. S. Bartell, J. Am. Chem. Soc., 92 (1970) 5013, and references therein.

3 H. B. Burgi and L. S. Bartell, J. Am. Chem. Soc, 94 (1972) 5236, 5239.

4 For a review, see W. McFarlane, Quart. Rev. Chem. Soc., 23 (1969) 187.

5 U. Hupbach, H. Frischleder and H. Helbig, Mol. Phys., 16 (1969) 593. 
6 C. S. Foote, Tetrahedron Lett., 9 (1963) 579.

7 K.-Mislow, Tetrahedron Lett., 22 (1964) 1415.

8 L. Pauling and L. O. Brockway. J. Am. Chem. Soc;, 59 (1937) 1223.

9 R. L. Livingston, C. Lurie and C. N. R. Rao, Nature, 185 (1960) 458.

10 E. A. Roth and L. S. Bartell (unpublished research); L. S. Bartell, Am. Cryst. Assoc., 2 (1966) 134.

11 B.-Beagley, D. P. Brown and J. J. Monaghan, J. Mol. Struct, 4-(1969) 233.

12 W. Zeil, J. Haase and M. Dakkouri, Z. Naturforsch., 22a (1967) 1644 (German).

13 L. S. Bartell, in A. Weissberger and B. W. Rossiter (Eds.), Physical Methods in Chemistry, 4th edn., Interscience, New York, 1973.

14 W. F. Bradford, Ph.D. Thesis, University of Michigan, 1975.

15 L. Schafer, A. C. Yates and R. A. Bonham, J. Chem. Phys, 55 (1971) 3055.

16 R. A. Bonham and L. S. Bartell, J. Chem: Phys., 31 (1959) 703.

17 J. Karle and L. L. Karle, J. Chem. Phys., 18 (1950) 957; L. S. Bartell, D. A. Kohl,

B. L. Carroll and R. M. Gavin, Jr., J. Chem. Phys., 42 (1965) 3079.

18 L. S. Bartell and M. G. Anashkin, J. Mol. Struct, 17 (1973) 193.

19 L. S. Bartell, J. Chem. Phys., 23 (1955) 1219; K. Kuchitsu and L. S. Bartell, J. Chem. Phys., 35 (1961) 1945.

20 S. J. Cyvin and B. Vizi, Acta Chim. Acad. Sci. Hung., 64 (1970) 357.

21 S. J. Cyvin, Molecular Vibrations and Mean Square Amplitudes, Elsevier, Amsterdam, 1968.

22 W. F. Bradford, S. Fitzwater and L. S. Bartell, submitted to J. Mol. Struct.

23 D. W. J. Cruickshank and A. P. Robertson, Acta Cryst., 6 (1953) 698.

24 S. Fitzwater and L. S. Bartell, J. Am. Chiem. Soc., in press.

25 C. W. Bunn and E. R. Howells, Nature, 174 (1954) 549; C. W. Bunn and D. R. Holmes, Discuss. Faraday Soc., 25 (1958) 95.

26 P. Andersen and B. Andersen, Acta Chem. Scand., 20 (1966) 2728.

27 J. O. Halford, J. Chem. Phys., 24 (1956) 830.

28 B. Rozondia and I. Hargittai, J. Mol. Struct, 17 (1973) 53.

29 T. Karrenbrock, $P h . D$. Thesis, University of Michigan, 1975. 